\title{
PSYCHOLOGICAL THRESHOLDS, DEMAND AND PRICE RIGIDITY*
}

\author{
by \\ S. A. DRAKOPOULOS $\dagger$ \\ University of Aberdeen
}

\section{INTRODUCTION}

One of the main characteristics of Keynesian and neo-Keynesian economics is the idea of wage and price inflexibility. In the past decade, Keynesian theorists have attempted to build the microeconomic foundations of price and wage inertia. Much of their effort has been concentrated on the labour market where money illusion, implicit contracts, union wages, etc. have all been proposed. The product market seems to have received less attention but, nevertheless, a number of ideas have been put forward. Thus, cost structure, oligopolistic environment and asymmetric information are some of the reasons which, according to neo-Keynesians can cause price sluggishness (for a review, see Gordon, 1990). Very few theorists have attempted to connect the product side with the theory of the consumer. In this paper, we will attempt to provide an additional microeconomic explanation for price rigidities which is based on consumer theory.

In particular we will discuss the implications of having a consumer theory which puts emphasis on "threshold" behaviour towards prices and quantities. Although a few theorists have written on the subject of threshold in consumer theory, the analysis is rarely extended to the demand side. Still fewer economists have attempted to connect the concept of thresholds with macroeconomic phenomena. However, Kornai (1971) and Scitovsky (1941) should be noted for their work on thresholds in relation to non-continuous adaptation and the absence of wild price instability.

In this paper, we will demonstrate that a threshold-based demand curve can be derived from a hierarchical approach to consumer behaviour and also from a customs- or habits-oriented response to price by the consumer. Subsequently it will be shown that a threshold-based demand can be seen as an additional explanation for price rigidity. The method of discussion will mainly be diagrammatical. The purpose of the paper is not so much the formal construction of the curves, which can be found elsewhere (e.g., Gorman, 1971, and Chipman, 1971), but mainly to see the possible effects of threshold behaviour in the product market in general terms.

\footnotetext{
* Manuscript received 18.1.91; final version received 14.3.91.

†The author wishes to thank two anonymous referees of this Journal for their valuable comments and suggestions. Special thanks are also due to P. Murphy and T. Torrance.
} 
We will begin the discussion with a brief section concerning the idea of a threshold in the history of economic theory and demonstrating the relatively low attention which it has received by orthodox theorists. The second part will concentrate on the construction of threshold-based curves from consumer behaviour theory. The following section will consider the macroeconomic implications of such curves and their role with respect to the controversy between Walrasian and non-Walrasian economists.

\section{THE IDEA OF THRESHOLD IN ECONOMICS}

In the history of economic thought, formulations of the standard theory of consumer behaviour have tended towards the construction of an axiomatic scientific theory. The reason for this was to establish a neutral theory with minimum psychological connotations. This is visible in the works of Pareto and Fisher, who strove to minimize the explicit psychological underpinnings of the work of Jevons and Edgeworth (see Pareto, 1971; Fisher, 1965; Jevons, 1871; and Edgeworth, 1881). Many orthodox theorists would argue that eventually Samuelson's revealed preference theory provided a truly psychology-free consumer theory (see Samuelson, 1963, but also Wong, 1978).

However, a closer look at the standard axiomatic theories shows that one of the implicit assumptions of contemporary theory is that of Archimedian agents. This implies that the consumer compares and reduces everything to a common denominator: utility. In the terminology of axiomatic theories, it implies that all preferences can be substituted. In other words, there is complete substitutability of every good in the sense that the consumer is willing to sacrifice all of one good for higher quantities of another good. For instance, food can, in theory, be substituted completely for perfume. In formal terms, the Archimedian preferences can be stated as follows: There are two bundles of goods $x$ and $y$, and $P$ means "preferred to":

$$
\left(x_{1}, y_{1}\right) P\left(x_{2}, y_{2}\right)
$$

this can be reversed by increasing $x_{2}$. This implies that there exists an $x>x_{2}$ such that:

$$
\left(x, y_{2}\right) P\left(x_{1}, y_{1}\right)
$$

This approach has a long history in economics and it goes back to marginalist formulations. In particular, Jevons and Walras were keen to construct a theory which would resemble in rigour the physical science theories. The behaviour of the consumer was assumed to be mechanistic and predictable (see Jevons, 1871; Walras, 1965; and Mirowski, 1984). Thus, they attempted to reduce the complex aspects of the behaviour of the consumer to a single dimension. All of the consumer's choice could be explained in terms of automatic and all-embracing utility maximization (see Georgescu-Roegen, 1966, p. 191; Borch, 1968; and Sen and Williams, 1982). 
If we are willing to abandon the standard model of utility maximization, then the possibility of threshold-sensitive behaviour appears. A number of theorists such as Little (1950, 1957); Georgescu-Roegen (1966); Gorman (1971); Devletoglou (1971); Kornai (1971); Earl $(1983,1986)$ and others have discussed this possibility. The threshold-oriented behaviour can be divided into two categories. The first one is based on quantity (static) and the second one on price (dynamic). The quantity approach discards the Archimedian preferences and the price approach rejects the idea of perfect utility maximizing agents. Basically, the conceptual starting point of these two categories is that the consumer is not characterized by perfect substitutability or price sensitivity but has needs or habits which affect choices.

In the case of quantity, it is assumed that agents have a hierarchical structure of needs. First, they satisfy the primary needs; second, the secondary needs. This approach has long been present in economics in the sense that many writers have mentioned this possibility. The examples of Menger (1950); Marshall (1961); and, more recently, of Little (1957); Georgescu-Roegen (1966); Encarnacion (1964, 1983); Day and Robinson (1973); and Lutz and Lux $(1979,1988)$ are indicative. However, its important implications have passed largely unnoticed and most contemporary theorists have ignored it. This approach can claim backing from psychology where theorists have supported a hierarchical theory of wants or needs (see Maslow, 1954, and, for a review, Drakopoulos, 1990, and Earl, 1990). The character of the passage from one criterion to the other can be seen as threshold level. One can also see a similar approach in the idea of Rawlsian welfare functions, based on a minimum requirement (or social threshold) which relates to the least advantaged individual in the community (see Rawls, 1971, and Maslow, 1954). Furthermore, Canterberry (1979) uses a hierarchical system to study the welfare implications of inflation.

Before we proceed, it must be noted that there are two types of hierarchical (lexicographic) choice. The first type, which can be found in some advanced texts, refers to a complete lexicographic ordering. Choice is made in terms of the highest priority need. The lower order needs come into the picture only when there is a tie between commodity bundles with respect to the first need. The second type, which is the concern of this paper, implies the setting of targets. The lower priority needs become relevant when the first need has reached a target (see Encarnacion, 1964). ${ }^{1}$ Neoclassical texts have

${ }^{1}$ Briefly, the basic difference between the strict and the target lexicographic ordering can be described formally:

$$
\begin{array}{ll}
\left(x_{1}, y_{1}\right) P\left(x_{2}, y_{2}\right) \quad \text { iff } \\
x_{2}<x_{1} \quad \text { (strict) } \\
x_{2}<x_{1}<x^{*} & \text { (target) }
\end{array}
$$


largely ignored this point and consider only the strict lexicographic ordering. Although we concentrate on the second type, it is indicative to get an idea of the treatment of such alternative choice models by advanced texts:

Although lexicographic orderings represent a perfectly reasonable system of choice, it is convenient to rule them out. (Deaton and Muellbauer, 1980, p. 27).

It seems that the Marginalist-based momentum towards a simplistic and mechanistic approach to consumer choice continues within modern theories.

The starting point of the second category of threshold behaviour is that the consumer does not modify his choices according to every change in price but only when price exceeds a certain limit. This has common points with the idea of matching behaviour in psychology, which is presented as an alternative to perfect maximizing behaviour (see Prelec, 1982). Also it draws from principles of psychophysics and from the idea of correspondence between physical stimulus and psychological sensations (see Dember and Jenkins, 1970). This approach can also be seen as a way of representing behaviour based on habits or customs or even a habitual way to deal with search or information costs.

\section{Threshold-Based Demand}

Hierarchical Needs

Before starting this section, a point of clarification is needed. Although there is a tendency to use the terms "needs" and "wants" as synonymous, there is a difference in the sense that a need implies something which is universally necessary while want implies a particular preference, a personal inclination (see, also, Georgescu-Roegen, 1966, pp. 190-198). This point might also be useful in the subsequent analysis of basic and non-basic goods.

As mentioned before, the starting point of the hierarchical approach is the idea that needs are not reducible. The standard implicit assumption that all goods can be substituted because all different needs can be reduced to utility is dropped. One can think of simple methods of needs hierarchy. Following Maslow (1954), for instance, we could start from basic material needs, proceeding to social needs and eventually to self-actualization needs. One could also follow a more specific classification: thirst, hunger, shelter, leisure. It can also be maintained that the needs lower in the hierarchy are likely to be common among men of different cultures. Needs higher in the hierarchy are likely to be common among people of the same culture (see Georgescu-Roegen, 1966, p. 198).

The economic translation of such a system will be the following: there are a number of criteria of choice and these criteria are based on the hierarchical structure of needs. For instance, if there is a choice of food (survival) and 
concerts (leisure), the individual prefers food first and, after his hunger has been satisfied (threshold), then the second criterion comes into the picture. ${ }^{2}$ As will be shown, this approach might have significant implications for the idea of price adjustment.

If we start from a very simple example of two goods, two criteria, the choice can be described formally: if there are two goods, $x$ (food) and $y$ (concerts), then the agent will operate in terms of the first need initially and of the second need after a threshold point $\left(x^{*}\right)$ where his hunger becomes less urgent:

$$
\left(x_{1}, y_{1}\right) P\left(x_{2}, y_{2}\right) \text { iff either }
$$

The graphical representation of this simple example is the following:

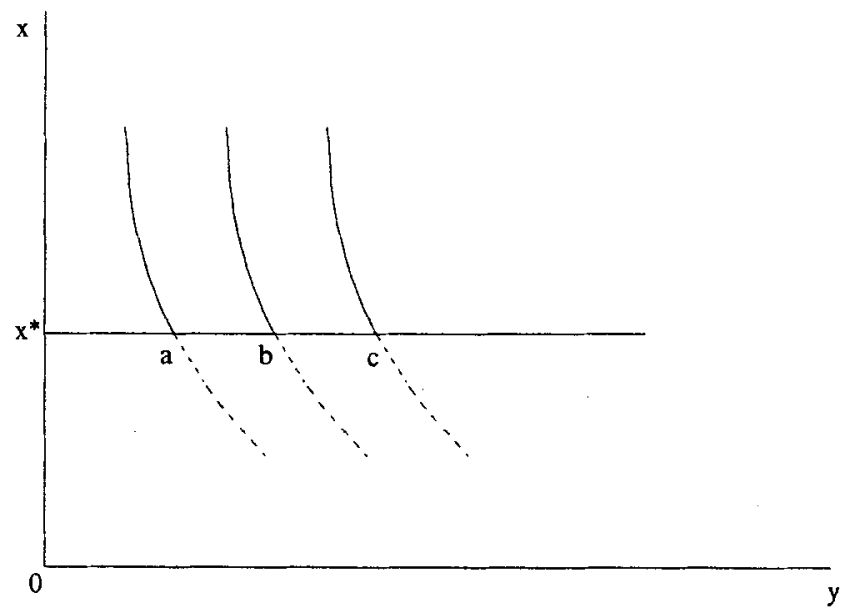

FiG. 1

Line $a b c$ has some characteristics of the indifference curve but cannot be called an indifference curve because the points on it are ordered (i.e., $b P a$ ).

${ }^{2}$ One can note a similarity of the hierarchical model with Stone's utility function or linear expenditure system. Although there is the common idea that there are subsistence goods which must be consumed first, Stone's specification allows allocation in consumption to take place only when specific subsistence goods are consumed. The general hierarchical model allows greater substitutability in the sense that goods can be both necessary and nonnecessary. (I am grateful to P. Murphy for this point; see also Stone, 1954.) 
However, the indifference characteristic is that all points above $a b$ are preferred to point $a$ and point $a$ is preferred to all points below the line $a b$. The horizontal slope of the line implies that under no circumstances will the agent substitute $x$ for $y$. Only when $x$ is at a certain limit does the preference for $y$ come into the picture. The second criteria are represented by the curves which, like $a b$, can be called quasi-indifference or behaviour curves. Due to the existence of those curves point $c$ is preferred to point $b$. This is a simple model with some substitutability (especially with respect to the second need) but, as we will show, there are other more realistic formulations with a higher degree of substitutability even with respect to the first need. It is easy to see that if the consumer has an income constraint which (for high prices of $x$ ) is less than the price of the necessary goods, the demand curve for good $x$ will be a rectangular hyperbola up to a point and then it will become linear. (If there is no income constraint the shape of the demand curve will be different but still kinked.) ${ }^{3}$

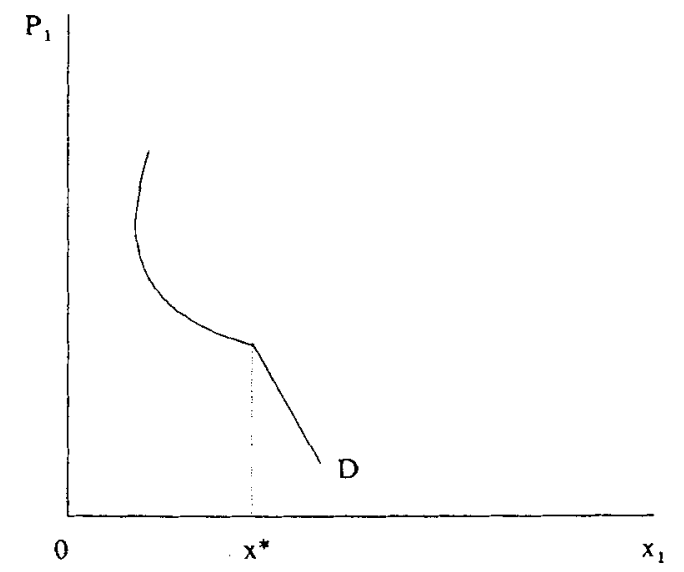

FiG. 2

$$
\begin{aligned}
& x_{1}=M / p_{1} \quad \text { for } \quad x_{1} \leqslant x^{*} \\
& x_{1}=a-b p_{1} \quad \text { for } \quad x_{1}>x^{*} \quad(a>0, b>0)
\end{aligned}
$$

As the price ( $p$ ) of $x$ falls, the agent spends all income $(M)$ on $x$ until he or she reaches point $x^{*}$ (threshold). After this point, a further fall in prices will induce a higher consumption of $x$ but a part of income is spent now on the other good, $y$.

${ }^{3}$ If there is no income constraint, then the shape of the demand curve will be as in Fig. 2 to the right of $x^{*}$, plus a vertical section at $x=x^{*}$ in place of the hyperbola. 
One can notice here that the first need is satisfied only by a particular good $(x)$, while the second need is met by both $x$ and $y$ (although the second need is satisfied better by $y$ ). The general idea implied here is that there are specific goods which satisfy particular needs, especially when the need is basic (necessary goods). One would expect that the need to eat will be satisfied by food only, whilst the need for entertainment could be met by a number of different categories of goods, food and concerts included. Furthermore, a change in the budgetary situation is likely to have significant effects on the agent's consumption plan. For instance, a price cut might result in a reallocation of expenditure between commodity categories, so as to enable the agent to satisfy additional needs which previously were unattainable because of budget limitations (Earl, 1983, pp.148-169, and 1986, pp. 258-263). A change in the budgetary situation coming from income might also reveal the consumer's perception of luxuries, necessities and inferior goods. For example, if there is an income rise, higher-quality goods replace lower-quality goods of the same category (e.g., moving from public transport to private cars, see Encarnacion, 1964; Day and Robinson, 1973). Related to these points is the idea of separation between generic goods and brand goods, which implies that the scope of the consumer's intolerance might differ between these two (this point can also be connected to the previous comment on the difference between needs and wants; see Lutz and Lux, 1979, pp. 68-69). ${ }^{4}$

We can extend this simple model by introducing three criteria corresponding to different types of needs. Thus we take two goods, mineral water $(x)$ and beer $(y)$, and we assume that mineral water satisfies the primary need to drink. After a threshold point $\left(x^{*}\right)$ the secondary need, which is taste, comes in to the picture. We assume that beer satisfies better the second criterion (or, in other words, although both goods satisfy taste, the consumer is inclined to beer). The third criterion represents a social need which arises after a threshold point $y^{*}$ and is satisfied better with mineral water. The choice model in this case will be the following:

$$
\begin{aligned}
& \left(x_{1}, y_{1}\right) P\left(x_{2}, y_{2}\right) \text { iff either } \\
& x_{2}<x_{1}<x^{*} \quad \text { or } \\
& x_{2}=x_{1} \leqslant x^{*} ; \quad y_{2}<y_{1} \quad \text { or } \\
& x_{2}<x^{*}<x_{1} \quad \text { or } \\
& x^{*}<x_{1}, x_{2} ; \quad y_{2}<y_{1}<y^{*} \text { or } \\
& x^{*}<x_{1}, x_{2} ; \quad y_{2}<y^{*}<y_{1} \quad \text { or } \\
& x^{*}<x_{1}, x_{2} ; \quad y_{2}, y_{1}>y^{*} ; \quad x_{2}<x_{1}
\end{aligned}
$$

${ }^{4}$ I am grateful to an anonymous referee for this point. 
The graphical representation of the above will be:

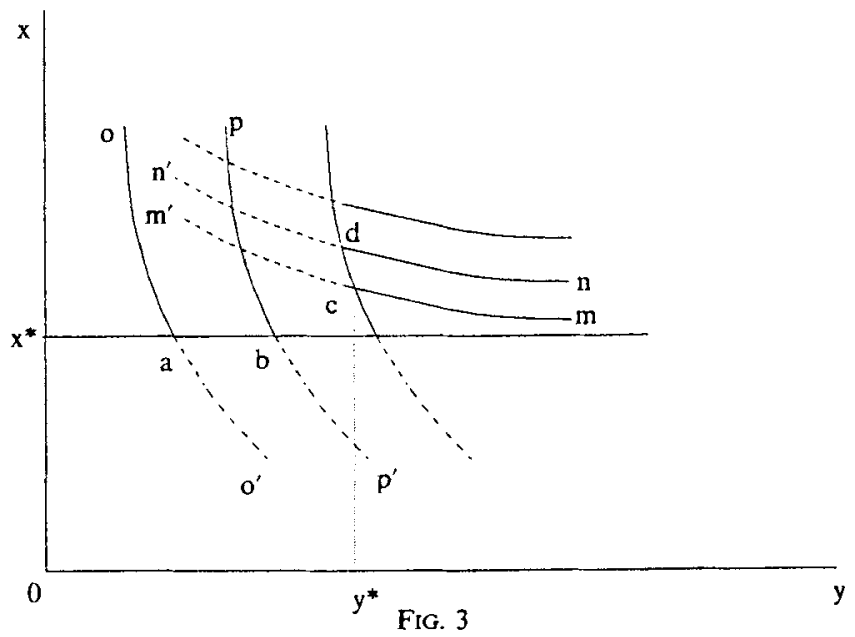

After the threshold point has been reached, the quasi-indifference curves of the type $o o^{\prime}$ and $p p^{\prime}$ come into the picture. Also, other things being equal, the third criterion is represented by the type $\mathrm{mm}^{\prime}$ and $\mathrm{nn}^{\prime}$. Thus the slope of the quasi-indifference curves $o o^{\prime}$ and $p p^{\prime}$ represents the secondary preference of the consumer for $y$ (beer). Also the slope of the quasi-indifference curves $\mathrm{mm}^{\prime}$ and $n n^{\prime}$ represents the third criterion, which is the preference for mineral water. It is evident from the choice model that point $b$ is preferred to point $a$; point $c$ is preferred to point $b$; and point $d$ is preferred to point $c$.

We can introduce substitutability even with respect to the first criterion if we assume that both beer and mineral water satisfy the need to drink (thirst) but, after a certain threshold has been reached $\left(d^{*}\right)$, taste is satisfied better with beer and the social need better with mineral water. In this case, the quasiindifference curves representing the first need will be very close to true indifference curves. If the threshold for the need to drink is $d$ then we have:

$$
x+y=d
$$

The choice model will be:

(2) $x_{2}+y_{2}=x_{1}+y_{1} \leqslant d^{*} ; \quad y_{2}<y_{1} \quad$ or

(3) $x_{2}+y_{2}<d^{*}<x_{1}+y_{1} \quad$ or

(4) $d^{*}<x_{1}+y_{1} ; \quad x_{2}+y_{2} ; \quad y_{2}<y_{1}<y^{*}$ or

(5) $d^{*}<x_{1}+y_{1} ; \quad x_{2}+y_{2} ; \quad y_{2}<y^{*}<y_{1}$ or

(6) $d^{*}<x_{1}+y_{1}, x_{2}+y_{2} ; \quad y^{*}<y_{2}, y_{1} ; \quad x_{2}<x_{1}$ 
The graphical representation of the above will be the following:

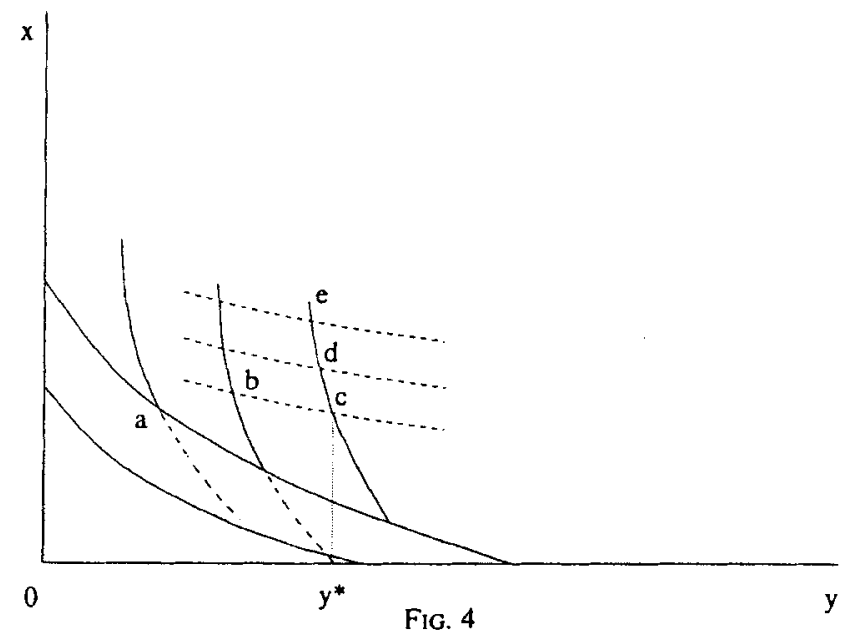

It can be seen here that

$$
b P a, \quad c P b, \quad d P c, \text { and } e P d
$$

The introduction of budget lines here can give us the demand curves. In particular, budgetary situations and quasi-indifference curves resemble suboptimal or corner solutions in the theory of exchange. Gorman (1971) has set the additional assumptions required for the analysis in budgetary situations and for the derivation of the demand curves. The main postulates are: convexity, absence of neuroses and uniqueness. (One can even think in terms of a "quasi utility" or criterion utility; see Gorman, 1971, and Fishburn, 1974). On the basis of the same points, the budgetary choice of the above graph will produce a kinked demand curve similar to the one derived from the very simple model shown in the beginning of this section.

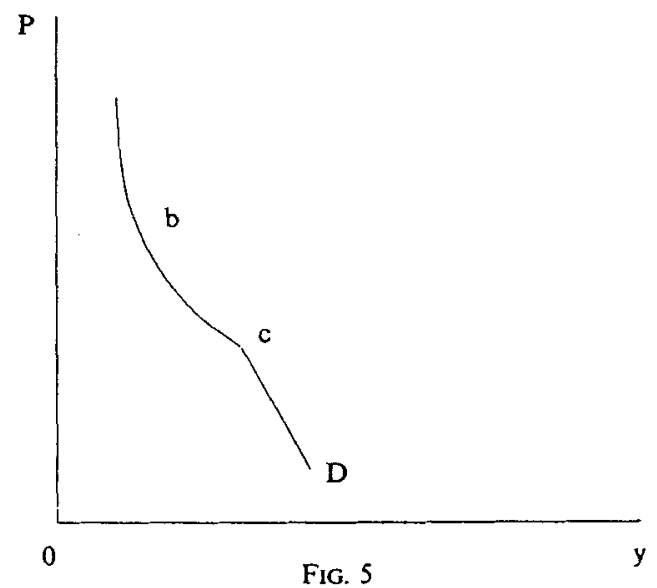


The point of the kink will be where the second criterion is satisfied and the next one becomes important. This is also a general result in a thresholdbased choice model. The point of the kink coincides with the threshold level. The change of slope of the demand curve reflects the change in relative efficacy of the good to satisfy subsequent needs. One could also argue that it is likely to get multi-kinked demand curves, especially when certain goods are perceived to satisfy a number of needs. For instance, in our initial example, good $x$ (food) can also satisfy the need for entertainment after a certain threshold point.

\section{Price-Based Threshold}

The previous discussion had as a basis a quantity-oriented threshold approach. The threshold idea can also be seen when we have changes in price (this is a dynamic approach). In this approach, the concept of threshold is explicitly included in the demand function. (It has to be noted that the construction of such a demand function does not come from an analytic consumer theory.)

One can also find support from modern psychology about this sort of threshold. In particular, the Weber-Fechner Law in psychophysics suggests that, as a physical stimulus increases logarithmically, the sensation quality of that stimulus as perceived by the observer increases arithmetically. This implies that there is a threshold before the subject can detect differences in stimuli. For instance, if one holds a $10 \mathrm{~kg}$. weight, it will take an additional $1 \mathrm{~kg}$. before the difference is detected (see Osgood, 1953, and Dember and Jenkins, 1970). This idea from psychophysics has been taken by Carlson and Parkin (1975) in their analysis of inflationary expectations where they make use of the Weber-Fechner Law to price movements.

Following Devletoglou and Demetriou (1967) and Devletoglou (1971), a threshold-based demand function can take the form:

$$
q_{t}=q\left[p_{t}-g\left(p_{t}-p_{o}\right), a_{t}\right]
$$

where

$$
g=\left\{\begin{array}{l}
1 \\
0
\end{array}\right\} \text { if }\left|\frac{p_{t}-p_{o}}{p_{0}}\right| \quad\left\{\begin{array}{l}
< \\
\geqslant
\end{array}\right\} A T
$$

$g$ describes the threshold, $p_{t}$ the price at time $t, p_{o}$ the price of a base year, $a_{t}$ an exogenous variable, $T$ the time period and $A$ the price threshold per unit of time. It is clear that a threshold range of price indifference is implied. When relative price changes are perceived by the consumer to be small, one expects the response in quantity demanded to be sticky (see Devletoglou, 1971, pp. 20-24). Moreover one expects that the threshold will be wider when the agent perceives the level of prices to be low and narrow when the level of prices is perceived to be high. This reaction can be connected with what Thaler (1980) calls "Mental Illusions": consumers' perceptions of changes are 
likely to be different from the actual changes. For instance, a discount might be treated differently from a surcharge. Related to this point is the use of price ranges as an attention-confining device. The consumer might set upper and lower limits in which the good is expected to be found. The idea of the price range is also relevant to the previous section because it might determine which priorities are met (see Earl, 1986, pp. 259-260). Generally, the threshold-based demand function will not lead to the same equilibrium as the traditional approach. The demand curve will have small kinks and kinks are likely to be larger for lower prices.
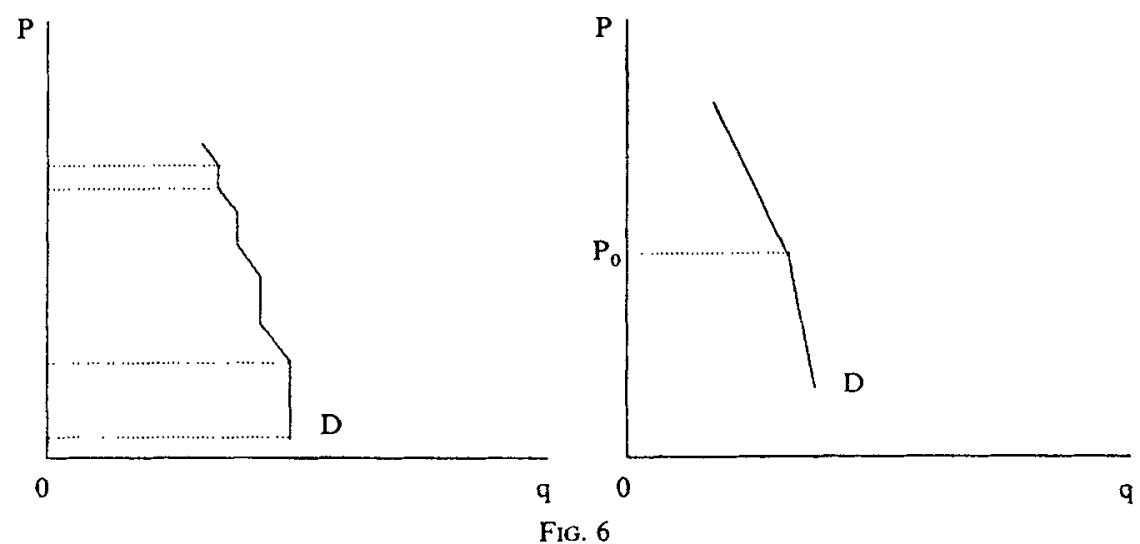

It is likely that the consumer will be much more sensitive (and thus the threshold will be smaller) at high levels of prices. Moreover, the consumer is likely to be much less sensitive (large threshold) when prices are relatively low or perceived to be low. A good approximation of this situation will be a demand function which will be more elastic for prices higher than a certain price, $p_{o}$, thus reflecting the agents' greater sensitivity. The demand will be more inelastic for prices lower than $p_{o}$, reflecting the agents' lower sensitivity.

The demand function described above and the ones described earlier have two different starting points. The first type of demand curves refers to the static choice between two goods (quantity-oriented) and the second one refers to the consumer response to dynamic changes in stimulation (change in price). As was pointed out, both approaches are based on the psychological threshold idea. It was also seen that both approaches are likely to produce demand curves with kinks which reflect the threshold-sensitive behaviour.

\section{Possible Macroeconomic Implications}

In this section, we will argue that the individual kinked demand curves are likely to have an impact on market demands. Also it will be shown that this impact might give Keynesian results in the sense of price inertia. 
Even if it is assumed that only part of the population is characterized by threshold behaviour, it is still likely that the total demand will be kinked. An additional argument for this is that the impact of the threshold-sensitive conduct is found not to cancel out in the aggregate but rather to expand hyperbolically. Devletoglou and Demetriou (1967, p. 352) have applied the idea of threshold behaviour to location theory and they have found that such behaviour expands hyperbolically (hyperbolic fan). This is reinforced by Akerlof and Yellen's (1985) point that even small deviations from the standard neoclassical agent can have first-order consequences. They demonstrate that non-rational (in the neoclassical sense) behaviour leads to changes in equilibrium (relative to equilibrium with full maximization) which are first order, that is, which vary proportionately with the shift parameter. $D_{k}$ is the kinked demand, $D_{n}$ is the normal demand and $D$ is the total demand curve.
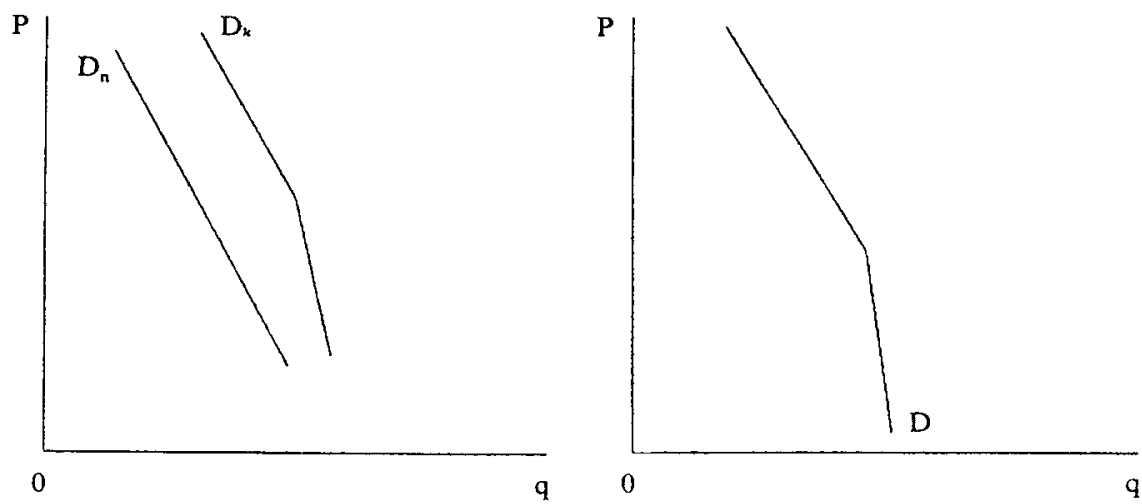

FIG. 7

The total demand equation will be the standard kinked demand:

with

$$
\begin{aligned}
D=f(q) & =f_{1}(q), q \leqslant \bar{q}, f_{1}^{\prime}<0 \\
& =f_{2}(q), q \geqslant \bar{q}, f_{2}^{\prime}<0
\end{aligned}
$$

$$
f_{1}^{\prime}(q)>f_{2}^{\prime}(q)
$$

(for an extensive discussion of the kinked demand, see Reid, 1981).

One can still argue that there is a possibility that the kinks will cancel out in the aggregate if we take into account the different points at which the threshold occurs. It can be maintained, however, that it is quite possible that the threshold levels might be similar for certain categories of goods (necessary and luxury goods) for large groups of the population with similar incomes (see, also, Little, 1957, and Georgescu-Roegen, 1966).

Before proceeding, it might be interesting to note that Pasinetti and Canterbery have given some attention to specific macroeconomic 
implications of hierarchical needs. Although their approach has some differences (very limited substitutability), they have given some indication of the macroeconomic consequences. Pasinetti (1981) argues that the investigation of technical progress must necessarily imply some hypotheses on the evolution of consumer (hierarchical) preferences as income increases. Canterbery (1979) associates hierarchical needs with the quality of inflation, its welfare effects and the production level of non-basic goods.

Price rigidities are a widespread phenomenon in modern economies as empirical research has shown. In particular, empirical studies of industrial countries have provided strong indications that the aggregate price level declines less than a fall in nominal demand (see Carlton, 1986, and Gordon, 1990). A number of theorists have provided explanations such as imperfect market structure or imperfect information for these rigidities (for a review, see Gordon, 1990).

Having in mind the above construction of the demand curve, one can offer an additional explanation for price stickiness.

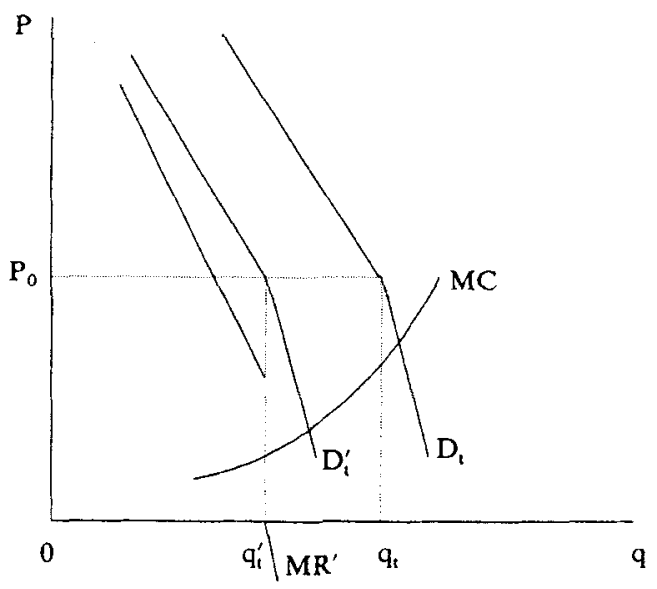

FIG. 8

A fall in demand due to a recession will cause a shift to the left from $D_{t}$ to $D_{t}^{\prime}$ (Fig. 8). It is very likely that the angle of the demand curve will remain at the same point. It is also likely that because of the large range of the vertical $M R$ the firm will hold its price at $P^{o}$ while quantity will fall from $q t$ to $q^{\prime} t$. (Smith and Neale, 1971, maintain that in the case of the kinked demand the marginal cost must always pass through the Marginal Revenue gap; for a general discussion of the macroeconomic implications of kinked demand curves, see Blanchard and Fischer, 1989.) Moreover, in the case of fixed capacity, price inertia can result in a non-market clearing situation. 
The above situation is similar to other approaches to the kinked demand curve. The first example is the well-known Sweezy's model where the idea of the kinked demand is based on the different perception of the firms in imperfect markets (see Sweezy, 1939). More recently, Okun (1981) has derived a kinked demand curve from the assumption of consumer loyalty. According to Okun, customers can be divided into those who had previously shopped at a firm (repeaters) and those with no such experience (random shoppers). The first group has a kinked demand curve while the second has a continuous one. It has to be noted that the idea of similar groups producing a demand curve with a kink can be seen as additional support for the aggregate threshold model. Negishi $(1979,1985)$ also derives a kinked demand curve from the assumption of asymmetric reaction of customers in the case of competitive firms. Lower prices asked for by a supplier may not be fully advertised to customers currently buying from other suppliers who are maintaining the current prices; at the same time, a higher price imposed by the same supplier induces present customers to leave in search of other suppliers. Braverman (1980) and Stiglitz (1979) also have an explanation of the kink, based on informational asymmetries. Scitovsky (1978) maintains that habits can cause a downward-pointing kink to the demand curve (i.e., addiction asymmetry stems from the tendency to acquire habits to consume much more easily than to abandon them). Furthermore, Scitovsky's ideas on asymmetric demand have been applied with reference to the demand for basic commodities. The empirical findings with respect to the demand for milk have indicated the presence of asymmetries in the form of the Keynesian idea of money illusion (Rutherford, Hocking and Ingham, 1985).

It is also interesting to note that these basically Keynesian results coming from threshold behaviour are not very far from Keynes's ideas. In particular, in his discussion of consumption when he analyses the relation between income and savings, the idea of a higher proportion of income saved as real income increases is justified in the following terms:

... it is also obvious that a higher absolute level of income will tend, as a rule, to widen the gap between income and consumption. For the satisfaction of the immediate primary needs of a man and his family is usually stronger motive than the motives towards accumulation, which only acquire effective sway when a margin of comfort has been attained. (Keynes, GT, p. 97).

It is clear that what Keynes has in mind here is not far from the above hierarchical approach which we described. Additional evidence in the same spirit can be found in the following quotation: "For a man's habitual standard of life usually has the first claim on his income and he is apt to save the difference which discovers itself between his actual income and the expense of habitual standard." (Keynes, GT, p. 97). Moreover, Keynes's attention to the importance of social habits and habitual behaviour in general is also another 
indication of the proximity of threshold-based behaviour to Keynes's thought. (See Keynes, GT, pp. 93, 98, and, for a discussion of Keynes's views on habitual behaviour, Lawson, 1985.)

One can make a connection between Keynes's views on habitual behaviour and hierarchical needs and Duesenberry's income hypothesis. There are clear indications that Duesenberry (1949, pp. 19-22) supports a hierarchical view of consumer behaviour since he discusses consumption choices in terms of physical, social and cultural needs. Moreover, it can be argued that Duesenberry's idea that consumption is related to the highest level of income previously reached indicates a form of threshold effect which can be reinforced by his continuous emphasis on habits and social customs.

\section{CONCLUSiON}

The primary purpose of this paper was to demonstrate an additional explanation of the case of price inflexibility in the product side of the economy. It was seen that the introduction of the threshold concept in the theory of consumer choice can produce kinked demand curves which, in turn, can account for price rigidity. It was also argued that the idea of threshold behaviour has considerable support in psychology. Subsequently, the concept of the threshold was divided into two parts: the quantity side, where it was discussed in terms of a hierarchical structure of preferences, and the price side, where threshold was analysed in terms of dynamic choice.

Both approaches are likely to give kinked demand terms similar to the ones which are derived from other ideas like informational asymmetries. The results here can provide an additional explanation of observed price stickiness in the sense that they originate from threshold behaviour, something which has not received proper attention in this context. Moreover, there are indications that the idea of threshold behaviour is not very far from Keynes's economic thought. Thus, although the concept of psychological threshold is not new, very few theorists have connected it with kinked demand curves and price sluggishness on the product side.

\section{REFERENCES}

Akerlof, G. and Yellen, J. (1985). "Can Small Deviations from Rationality Make Significant Differences to Economic Equilibria?", American Economic Review, Vol. 75, No. 4, pp. 708-720.

Blanchard, O. and Fischer, S. (1989). Lectures on Macroeconomics, Cambridge, Mass., The M.I.T Press.

Borch, K. (1968). The Economics of Uncertainty, Princeton, N.J., Princeton University Press.

Braverman, A. (1980). "Consumer Search and Alternative Market Equilibria", Review of Economic Studies, Vol. 47, No. 3, pp.487-502.

Canterbery, R. (1979). "Inflation, Necessities and Distributive Efficiency" in J. 
Gapinski and C. Rockwood (eds.), Essays in Post-Keynesion Inflation, Cambridge, Mass., Ballinger.

Carlson, J. and Parkin, M.(1975). "Inflation Expectations", Economica, Vol.42, No. 166, pp. 123-138.

Carlton, D. (1986). “The Rigidity of Prices”, American Economic Review, Vol. 76, No. 4, pp. $637-658$.

Chipman, J. (1971). "On the Lexicographic Presentation of Preference Orderings" in J. Chipman et al. (eds.), Preferences, Utility, and Demand, New York, Harcourt Brace Jovanovich.

Day, R. and Robinson, S. (1973). "Economic Decision and L** Utility" in J. Cochrane and M. Zeleny (eds.), Multiple Criteria Decision Making, Columbia, S.C., University of South Carolina Press.

Deaton, A. and Muellbauer, J. (1980). Economics and Consumer Behaviour, Cambridge, Cambridge University Press.

Dember, W. and Jenkins, J. (1970). General Psychology, Englewood Cliffs, N.J., Prentice-Hall.

Devletoglou, N. (1971). Consumer Behavior: An Experiment in Analytical Economics, London, Harper and Row.

Devletoglou, N. and Demetriou, P. (1967). "Choice and Threshold: A Further Experiment in Spatial Duopoly", Economica, Vol. 34, No. 136, pp. 351-371.

Drakopoulos, S. (1990). "The Implicit Psychology of the Theory of the Rational Consumer: An Interpretation", Australian Economic Papers, Vol.29, No. 55, pp. 182-198.

Duesenberry, J. (1949). Income Saving and Consumer Behavior, Cambridge, Mass., Harvard University Press.

Earl, P. (1983). The Economic Imagination, Brighton, Wheatsheaf Books.

Earl, P.(1986). Lifestyle Economics, Brighton, Wheatsheaf Books.

Earl, P. (1990). "Economics and Psychology: A Survey", Economic Journal, Vol. 100, No. 402, pp. 718-755.

Edgeworth, F.(1881). Mathematical Psychics, London, Kegan Paul.

Encarnacion, J. (1964). "A Note on Lexicographical Preferences", Econometrica, Vol. 32, No. 1-2, pp. 215-217.

Encarnacion, J. (1983). "Social Values and Individual Choices", Journal of Economic Behavior and Organization, Vol. 4, No. 2-3, pp. 265-275.

Fishburn, P. (1974). "Lexicographic Orders, Utilities and Decision Rules: A Survey", Management Science, Vol. 20, No. 11, pp. 1442-1471.

Fisher, I. (1965). Mathematical Investigations in the Theory of Value and Price, New York, Augustus M. Kelley.

Georgescu-Roegen, N.(1966). Analytical Economics, Cambridge, Cambridge University Press.

Gordon, R.(1990). "What is New-Keynesian Economics?", Journal of Economic Literature, Vol. 28, No. 3, pp. 1115-1171.

Gorman, W. (1971). "Preference, Revealed Preference, and Indifference" in Chipman et al. (eds.), op. cit.

Jevons, S. (1871). The Theory of Political Economy, London, Macmillan.

Keynes, J. M. (1936). The General Theory of Employment, Interest and Money, London, Macmillan.

Kornai, J. (1971). Anti-Equilibrium, Amsterdam, North-Holland.

Lawson, T. (1985). "Uncertainty and Economic Analysis", Economic Journal, Vol. 95, No. 377, pp. 909-927.

Little, I. M. D. (1950). "The Theory of Consumer's Behaviour-A Comment", Oxford Economic Papers, Vol. 2, No. 1, pp. 132-135.

Little, I. M. D. (1957). A Critique of Welfare Economics, Oxford, Clarendon Press. 
Lutz, M. and Lux, K. (1979). The Challenge of Humanistic Economics, Menlo Park, Ca., Benjamin/Cummings.

Lutz, M. and Lux, K. (1988). Humanistic Economics: The New Challenge, New York, Bootstrap Press.

Marshall, A. (1961). Principles of Economics (9th Edition), London, Macmillan.

Maslow, A. (1954). Motivation and Personality, New York, Harper and Row.

Menger, C. (1950). Principles of Economics (translated by J. Dingwall and B. Hoselitz), Glencoe, Ill., The Free Press.

Mirowski, P. (1984). "Physics and the Marginalist Revolution", Cambridge Journal of Economics, Vol. 8, No.4, pp. 361-379.

Negishi, T. (1979). Microeconomic Foundations of Keynesian Economics, Amsterdam, North-Holland.

Negishi, T.(1985). Economic Theories in a Non-Walrasian Tradition, Cambridge, Cambridge University Press.

Okun, A. (1981). Prices and Quantities: A Macroeconomic Analysis, Washington, D.C., The Brookings Institution.

Osgood, C. (1953). Method and Theory in Experimental Psychology, New York, Oxford University Press.

Pareto, V. (1971). Manual of Political Economy (translated by A. Schwier), London, Macmillan.

Pasinetti, L. (1981). Structural Change and Economic Growth, Cambridge, Cambridge University Press.

Prelec, D. (1982). "Matching, Maximizing and the Hyperbolic Reinforcement Function", Psychological Review, Vol. 89, No. 3, pp. 189-230.

Rawls, J. (1971). A Theory of Justice, Cambridge, Mass., Harvard University Press.

Reid, G. (1981). The Kinked Demand Curve Analysis of Oligopoly, Edinburgh, Edinburgh University Press.

Rutherford, R., Hocking, A. and Ingham, D. (1985). "Demand Asymmetry and Money Illusion with an Example-Milk", Journal of Agricultural Economics, Vol.36, No. 3, pp. 377-384.

Samuelson, P. (1963). Foundations of Economic Analysis, Cambridge, Mass., Harvard University Press.

Scitovsky, T. (1941). "Capital Accumulation, Employment and Price Rigidity", Review of Economic Studies, Vol. 8, No. 1, pp. 69-88.

Scitovsky, T.(1978). "Asymmetries in Economics", Scottish Journal of Political Economy, Vol. 25 , No. 1, pp. 32-46.

Sen, A. and Williams, B. (1982). "Introduction" in Sen and Williams (eds.), Utilitarianism and Beyond, New York, Cambridge University Press.

Smith, S. and Neale, W. (1971). "The Geometry of Kinky Oligopoly", Southern Economic Journal, Vol. 37, No. 3, pp. 276-282.

Stiglitz, J. E. (1979). "Equilibrium in Product Markets with Imperfect Information", American Economic Review, Papers and Proceedings, Vol. 69, No. 2, pp. 338-345.

Stone, R. (1954). "Linear Expenditure Systems and Demand Analysis", Economic Journal, Vol. 64, No. 255, pp. 511-527.

Sweezy, P. (1939). "Demand under Conditions of Oligopoly", Journal of Political Economy, Vol. 47, No. 4, pp. 568-573.

Thaler, R. (1980). "Toward a Positive Theory of Consumer Choice", Journal of Economic Behavior and Organization, Vol. 1, No. 1, pp. 39-60.

Walras, L. (1965). Elements of Pure Economics, (translated by W. Jaffe), London, Allen and Unwin.

Wong, S. (1978). The Foundations of Paul Samuelson's Revealed Preference Theory, London, Routledge. 